\title{
Contribuições ao processo de (re)significação da Educação Física escolar: dimensões das brincadeiras populares, da dança, da expressão corporal e da ginástica
}

\author{
Ieda Parra Barbosa-Rinaldi* \\ Larissa Michelle Lara* \\ Amauri Aparecido Bássoli de Oliveira***
}

\begin{abstract}
Resumo: Este texto visa apresentar reflexões didático-pedagógicas para a educação física escolar a partir do núcleo "o movimento em expressão e ritmo", proposto por Oliveira (2004). Tais reflexões envolvem aspectos conceituais, campo de conhecimento e orientações metodológicas para o trato com os seguintes saberes: brincadeiras populares, dança, expressão corporal e ginástica. $\mathrm{O}$ intuito dessa abordagem teórica é propor encaminhamentos que possam subsidiar o trabalho do professor, instigando-o ao diálogo com os conhecimentos rítmico-expressivos e, consequentemente, com sua materialização no cotidiano escolar.

Palavras-chave: Educação fundamental. Conhecimento. Educação Física. Jogos e brinquedos.
\end{abstract}

\section{INTRODUÇÃO}

\author{
Eu vi o menino correndo, eu vi o tempo \\ Brincando ao redor do caminho daquele menino [...]
}

Caetano Veloso

(Re)significar a educação física escolar não é, necessariamente, torná-la nova, como se as formas antigas e as atuais não tivessem seus méritos e suas características interventoras. Significa, sim, acirrar a percepção para saberes que ainda são postos à margem do sistema escolar, caracterizados pelas brincadeiras populares, pela dança, pela

*Professora Doutora do Departamento de Educação Física da Universidade Estadual de Maringá. Maringá, PR, Brasil. E-mail: parrarinaldi@hotmail.com

"Professora Doutora do Departamento de Educação Física da Universidade Estadual de Maringá. Maringá, PR, Brasil. E-mail: Imlara@uem.br

-"Professor Doutor do Departamento de Educação Física da Universidade Estadual de Maringá. Maringá, PR, Brasil. E-mail: aaboliveira@uem.br 
expressão corporal, pela ginástica, entre outras manifestações da cultura. É nesse sentido que a educação física precisa ser constantemente pensada no contexto da escola, sempre numa dinâmica que se traduza em mudanças e compromisso profissional para com a área.

Como forma de contribuir com uma dimensão do conhecimento por vezes esquecida, mediante o poder quase que imperioso da racionalidade cognitiva, o estudo procura trazer elucidações acerca da produção em educação física, do acesso aos saberes sistematizados, das práticas culturais estético-expressivas a ser tratadas e dos conhecimentos próprios ao núcleo "o movimento em expressão e ritmo". ${ }^{1}$ Tal intuito dá-se como forma de estabelecer diálogo com o professor que atua na escola, de modo que este desenvolva conhecimentos da cultura que possam ir além da prática do esporte, dando outros sentidos/significados à vida do aluno.

Por serem muitas as manifestações rítmicas e expressivas, o texto em questão toma por foco apenas algumas delas no sentido de facilitar a condução das reflexões. Optamos pelo trato com as brincadeiras populares, com a dança, com a expressão corporal e com a ginástica por fazerem parte, mais diretamente, de nossas incursões investigativas e atuação profissional. Estes saberes serão abordados a partir do que é considerado prioritário na prática docente, como a historicidade, a capacidade estético-expressiva e rítmica, a relação dos conhecimentos com um homem único/múltiplo e dialógico. Tais considerações acerca das manifestações culturais não se colocam de forma isolada, mas se relacionam continuamente, marcadas por linhas divisórias tênues. É essa característica que nos leva a uma abordagem simultânea destes conteúdos, por vezes, interdependentes.

Longe de parecer algo pronto e acabado, o estudo contém análises que estão abertas a outros processos de comunicação. É resultante de nossas experiências profissionais e, também, de projetos de extensão e pesquisa em escolas. Sendo assim, esperamos que essas incursões possam promover reflexões, inquietações e incitar mudanças. Que novos desafios sejam postos diariamente à ação pedagógica do

$1 \mathrm{O}$ núcleo "O movimento em expressão e ritmo" encontra-se vinculado à proposta desenvolvida por Oliveira (2004) para a educação física escolar, e será explicitado ao longo do texto.

Movimento, Porto Alegre, v. 15, n. 04, p. 217-242, outubro/dezembro de 2009. 
professor, pois é necessário vivacidade para desconfiar do óbvio, buscar o inusitado e construir uma prática diferenciada junto à educação física escolar.

\section{A PRODUÇÃO E O ACESSO AO CONHECIMENTO SISTEMATIZADO NA EDUCAÇÃO FíSICA ESCOLAR}

A produção do conhecimento na educação física é um fenômeno histórico, complexo, de íntima relação com os contextos políticos e sociais. Sua construção retrata os saberes que se dão por meio da ação do homem no mundo ao se apropriar e se relacionar com ele. A partir da assimilação e reelaboração dos conhecimentos constroem-se instrumentos de ação para a prática social concreta. A necessidade da socialização do conhecimento institucionalizado e de sua reapropriação pela sociedade que o produziu conduz os indivíduos a recuperar o seu núcleo científico, sua objetividade e universalidade com vistas a construir uma realidade social desejável e melhor para todos.

A aquisição dos conhecimentos considerados necessários para a humanidade (de significado universal ${ }^{2}$ ), em sua forma institucionalizada, tem na escola seu espaço clássico. Não obstante, é imprescindível que a reelaboração dos conhecimentos promova a emancipação humana, o que de fato nem sempre acontece. Isto porque, a escolha e o trato dos diferentes conhecimentos podem se dar de formas antagônicas, refletindo a direção epistemológica da prática pedagógica. Um breve exemplo disso se dá na educação física, quando o professor vê no movimento humano apenas um simples gesto mecânico e automatizado, ou quando o percebe como manifestação artística, livre, criativa, sensível e subjetiva.

Nossa preocupação com esta abordagem dá-se na direção do não esvaziamento do conhecimento, haja vista que este poderia perpetuar desigualdades sociais e conduzir ao desconhecimento do homem de si mesmo. É indispensável evitar a inércia dos saberes, conduzindo o

\footnotetext{
2 Conhecimento universal é aquele transmitido nas escolas e em outros espaços de intervenção de maneira institucionalizada, entendendo que existem outros conhecimentos que são passados de gerações em gerações, assistematicamente, sendo consagrados por diferentes culturas.

Movimento, Porto Alegre, v. 15, n. 04, p. 217-242, outubro/dezembro de 2009.
} 
aluno a adquirir uma posição na qual possa tornar o conhecimento significativo para si e para a sociedade. "É essa a razão de ser das reivindicações no sentido de que a educação seja considerada como um relacionamento dialético entre o aluno e o ambiente" (KELLY, 1981, p. 71).

O processo educacional, sustentado na transmissão de conhecimentos prontos e desvinculados da realidade do aluno torna-se limitado, não oferecendo possibilidades de mudanças significativas, inviabilizando o rompimento com um processo civilizatório desumano. O acesso ao conhecimento universal acumulado é necessário para que os alunos possam dele se apropriar e estabelecer relação com sua existência individual e coletiva.

A educação, numa perspectiva emancipatória, pode possibilitar momentos nos quais o educando reconheça valores, experimente responsabilidade, cooperação, respeito, solidariedade, entre outros, contribuindo para que ele participe da organização social em que vive a partir da aprendizagem de conhecimentos que priorizem uma vida melhor dentro do seu núcleo social. Os saberes desenvolvidos na prática pedagógica, em sua maioria, devem vincular-se à realidade social e concreta dos alunos para que sejam significativos, de modo que haja assimilação de maneira consciente. Também devem ser conhecimentos clássicos que não se oponham ao que há de mais moderno, acompanhando o avanço da técnica e da ciência, tanto nacional como internacionalmente (SOARES et al., 1992).

Mesmo sabendo que seria impossível oferecer todos os conhecimentos relacionados à cultura de movimento na educação física escolar, entendemos que alguns deles precisam ser desenvolvidos e, de preferência, de forma tranversalizada, espiralada. Como afirma Cortella (2000), embora trabalhemos com a especificidade de uma área (que não pode ser reduzida à sua própria dimensão), outras dimensões (estéticas, éticas, religiosas, afetivas) estão presentes no cotidiano do aluno e, principalmente, nos saberes a ser tratados.

Como qualquer área do conhecimento, a educação física possui especificidades e acolhe a produção da cultura de movimento que se traduz em saberes e, mais especificamente, em conteúdos organizados de forma pedagógica na escola. Dentre as manifestações clássicas

Movimento, Porto Alegre, v. 15, n. 04, p. 217-242, outubro/dezembro de 2009. 
da cultura de movimento que compõem o roll de conhecimentos da educação física escolar encontram-se as brincadeiras populares, a dança, a expressão corporal e a ginástica, as quais podem originar valiosas experiências corporais. Isso desde que sua inserção no espaço escolar privilegie o entendimento de que estas práticas têm significado cultural e que novas formas de experimentação, em confronto com as tradicionais, poderão possibilitar que o aluno dê sentido próprio ao seu campo gestual e se perceba no mundo como agente.

O conhecimento fragmentado, sem relação com as outras áreas, deve ser substituído por um modo capaz de apreender a complexidade, o conjunto que perfaz o espaço escolar. Neste contexto, para que o professor possa ter uma atuação satisfatória que dê conta de desvelar as reais contradições presentes na prática educacional é necessário que o trato com o conhecimento seja mediado por um referencial teórico crítico. É preciso que os professores tenham competência técnica articulada com o compromisso político e que o processo educacional não seja um momento prévio, mas o próprio engajamento. Não basta aos alunos, simplesmente, conhecerem um ato ou acontecimento; é necessário analisá-lo, criticá-lo, atribuir a ele um significado atual.

Em análise, entendemos que o ato de ensinar pode ser, ao mesmo tempo, enriquecedor e repressor; dependerá da posição que o professor vá assumir frente ao trato com o conhecimento. Por isso, é mister romper com relações autoritárias rumo a uma prática pedagógica que permita o desenvolvimento da autonomia em nossos alunos, levandoos a ter consciência de sua capacidade crítica, ajudando-os a estudar, a pesquisar e saber o que fazer com os saberes que adquirem.

Além de seu papel formativo, adverte Pimenta (2002), o conhecimento pode permitir ao aluno uma ação contextualizada a partir do momento que este tem relação com o seu cotidiano, (re)significando-o e, ao mesmo tempo, sendo por ele (re)significado. O papel do professor é oferecer possibilidades de análise para que o aluno compreenda os contextos históricos, sociais, culturais e de si mesmo como agente social. Daí a importância de bem escolher os conhecimentos a ser tratados na educação física escolar, assumindo a responsabilidade de garantir aos alunos o acesso aos diferentes saberes, inclusive os estético-

Movimento, Porto Alegre, v. 15, n. 04, p. 217-242, outubro/dezembro de 2009. 
expressivos, de modo a provocar um processo de mudanças que conduza à (re)significação da educação física no espaço escolar.

\section{A EducaÇão Física e as PRÁticas CULTURAIS}

Muitos dos saberes tematizados pela educação física ligam-se diretamente a manifestações culturais brincantes, dançantes, expressivas e gímnicas que se colocam como formas de compreensão do homem e como meio educativo. Tal compreensão dá-se a partir de uma educação física compromissada com a formação humana, pautada em ações dialógicas, em que os elementos da cultura de movimento sejam valorizados como conhecimentos do cotidiano escolar.

Entendemos por práticas culturais as manifestações que, historicamente, foram concebidas como parte da produção dos homens em sociedade, reveladoras de seus saberes e formas de comunicação. $\mathrm{Na}$ educação física, essas práticas culturais se configuram pela gestualidade manifesta nos jogos, esportes, danças, ginásticas, lutas e brincadeiras, sendo o que mais especificamente caracteriza o nosso campo de atuação profissional.

O trato com as brincadeiras populares, com a dança, com a expressão corporal e com a ginástica dar-se-á não apenas por seus aspectos técnicos, mas, também, pela inter-relação com os diversos campos do conhecimento. O enfoque destas manifestações pelo viés histórico, sociológico, antropológico, filosófico, biológico, dentre outros, faz-se necessário não como forma de atrelamento a estas áreas, mas, sobretudo, por entendermos que estas dão o aporte necessário a uma prática educacional percebida em sua complexidade.

Embora partamos do entendimento de que o objeto é sempre mais do que o conceito, já que qualquer definição não dá conta de abarcá-lo naquilo que realmente significa, tentativas são feitas no sentido de orientar a ação pedagógica. Assim, a abordagem é dinâmica, flexível e temporalmente situada, sendo necessária para esclarecer o que estamos chamando de brincadeiras cantadas, dança, expressão corporal e ginástica. Por vezes, os conceitos se aproximam, haja vista que estamos falando de manifestações voltadas para o campo rítmico e expressivo.

Movimento, Porto Alegre, v. 15, n. 04, p. 217-242, outubro/dezembro de 2009. 


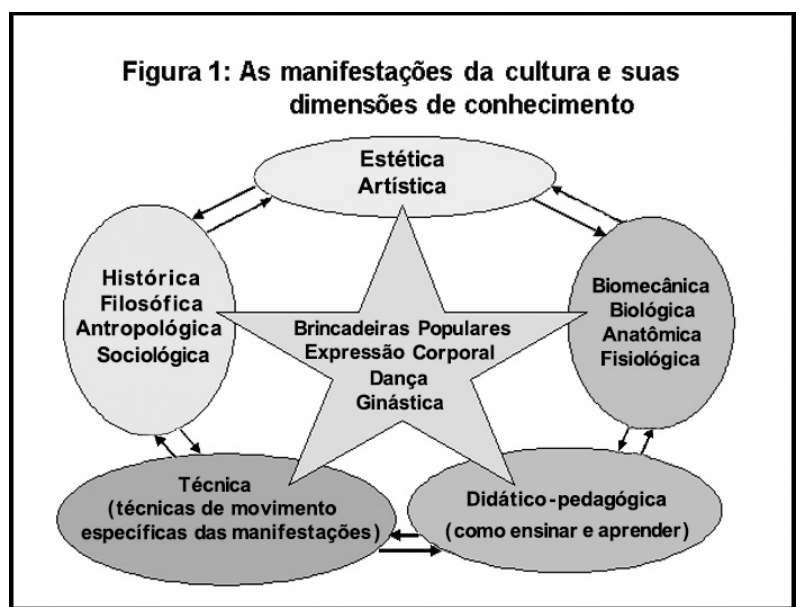

Figura 1. As manifestações da cultura e suas dimensões de conhecimento

As brincadeiras populares, como entendemos, são formas lúdicas de expressão de diferentes culturas, caracterizadas, em grande parte, pela presença do canto, do gesto, da roda, do ritmo, da competição, da vertigem, da sorte e/ou da mímica. Transmitidas ao longo das gerações, revelam a sabedoria popular, as crenças, o imaginário coletivo, não sendo diretamente ligadas aos ditames da indústria cultural.

Reconhecer nas manifestações culturais populares uma forma de driblar as altas investidas da indústria cultural é uma possibilidade de ação educacional comprometida com o sujeito em formação. Como lembra Zuin (1999, p. 1),

a essência do conceito de indústria cultural não só permanece atual, como também é relevante, sobretudo para a investigação dos mecanismos psicológicos determinados pelas relações sociais que exigem a universalização da semiformação e, por que não dizer, da nossa educação danificada.

O trabalho na escola com brincadeiras como gato e rato, amarelinha, lenço atrás, ciranda-cirandinha, escravos de Jó, balança caixão, pula carniça, dentre outros, é uma forma de valorizar a pluralidade cultural humana, ressaltando seus aspectos gestuais, musicais, rítmicos, histórico-sociais e expressivo-criativos. Este acervo popular contribui 
com a ampliação das técnicas corporais ${ }^{3}$ dos alunos, favorece o aprendizado de experiências em grupo, de cooperação e convivência com o outro, de respeito e de aprendizado da cultura em que se encontram inseridos.

Muitas formas de brincar com o corpo têm algo de dança, de ginástica, de capoeira. Daí as interconexões estabelecidas, em que uma manifestação é prioritária na concretização da outra. Como ocorre com outros termos da cultura, conceituar dança não deixa de ser complexo. É possível entendê-la como manifestação da cultura que se volta para poesia do movimento em sua relação com a técnica, a forma e o conteúdo, tomando por alicerce os saberes estético-expressivos, histórico-culturais e educacionais.

No contexto educativo, é fundamental pensar a dança a partir dos elos que estabelece e das transformações sociais que a originaram. Caracterizado por novas relações entre as pessoas, dissipando preconceitos e tabus acerca do corpo, o século XX revelou a diversidade de expressões culturais que conhecemos (dança de rua, jazz, balé, dança moderna e contemporânea, dança de salão, dança afro-brasileira, danças populares/folclóricas, dentre outras). E, assim, foram sendo criadas outras formas de manifestações conhecidas por dança, fruto da transformação de antigas práticas corporais ou resultante das necessidades contemporâneas de um novo homem.

Essas várias linguagens existentes não surgem sem seus problemas. Garaudy (1980, p. 179) acrescenta que, nessa sociedade, o movimento humano é explorado pelas forças econômicas e políticas na medida em que é integrado à concorrência, ao lucro e às violências do sistema. Nessa engrenagem, a dança não poderia desempenhar papel nenhum, nem tampouco receber incentivo. "Se não aceita ser um diver-

\footnotetext{
${ }^{3}$ O termo "técnicas corporais" é entendido a partir das contribuições do antropólogo Marcel Mauss (1974), como técnicas criadas pela cultura, portadora de significados característicos e materializadas na forma como o homem se relaciona socialmente, anda, alimenta-se, trabalha, corta os cabelos, enfim. Na educação física, as técnicas corporais são pensadas como formas gestuais próprias e representativas de determinadas manifestações da cultura, como os jogos, as brincadeiras, a dança, a ginástica, a expressão corporal, o esporte, em suas especificidades e em suas características identificatórias.
}

Movimento, Porto Alegre, v. 15, n. 04, p. 217-242, outubro/dezembro de 2009. 
timento, um prazer consumível, não apenas será marginalizada como se torna suspeita porque propõe um outro modelo de desenvolvimento humano, uma promessa de outros possíveis que põem em questão esse estilo de vida em sua totalidade". É justamente essa dança que não se submete às questões mercadológicas e que nem se converte em puro divertimento, que priorizamos no contexto educacional.

O desenvolvimento da dança não se dá desvinculado da expressão corporal. Mesmo não sendo sinônimos, já que cada manifestação apresenta suas especificidades, elas se complementam e, por vezes, se (con)fundem, de forma espontânea ou sistematizada. Conceitualmente, entendemos a expressão corporal como área que potencializa a gestualidade comunicativa dos indivíduos por meio da alfabetização do corpo, revelando sentimentos, desejos, pensamentos, conscientizando ações, posturas e gestos.

A expressão corporal é reveladora de épocas. Em cada período histórico o homem expressou-se diferentemente, exaltando ou rechaçando o corpo e seus sentimentos. Como campo de conhecimento próprio e técnica sistematizada, a expressão corporal é resultante da sociedade contemporânea, contribuindo para criticar formas de reprodução gestuais alienantes em diversas áreas do conhecimento. "A expressão corporal aparece como um meio de questionar a ideologia e os métodos da educação física. De abrir uma dimensão suscetível de contrabalancear a primazia da competição" (PUJADE-RENAUD, 1990, p. 79).

Embora haja expressão corporal em todas as nossas ações - na religiosidade, no trabalho, na vida social - focamos, mais especificamente, a expressão intencional, trabalhada em muitas modalidades de dança, teatro, ginástica, ou, materializada como campo de conhecimento próprio, ou seja, como conteúdo da educação física escolar, disciplina em cursos de graduação e pós-graduação, cursos de extensão, entre outros. Essa expressão corporal procura transformar um gesto simples em forma artística, com poder comunicativo, valorizada na interação com o outro, mesmo que numa linguagem abstrata e não linear. Ressalta aquilo que passaria despercebido e dá vida a cenas que, cotidianamente, seriam comuns. Pautada na necessidade de romper com o banal, com o igual, com o ausente de sentido/significado, a expres-

Movimento, Porto Alegre, v. 15, n. 04, p. 217-242, outubro/dezembro de 2009. 
são corporal se torna prioritária no trato educacional com as várias manifestações culturais.

Pensando nas inúmeras possibilidades de utilizar o corpo em sua forma expressiva voltamo-nos para a ginástica. Historicamente, é possível afirmar que a ginástica (métodos ginásticos) e a escola moderna nasceram praticamente juntas e com características típicas da sociedade burguesa e europeia dos séculos XVIII e XIX. A educação do corpo começa a acontecer na sociedade burguesa por meio da ginástica que é sistematizada entre os anos de 1800 e 1900. De acordo com Ayoub (2003, p. 32), tem início

a configuração de uma gestualidade própria da ginástica, o gesto gímnico, cujos significados estão apoiados na ciência e na técnica, assim como nos princípios de ordem e disciplina ditados pela burguesia.

Os métodos ginásticos que surgiram na Europa foram, de modo idêntico, implantados no Brasil. Sua inserção nas diferentes instituições de ensino aconteceu com as mesmas vinculações científicas de sua origem, marcadamente influenciada pelas ciências físicas e biológicas, sendo este o conteúdo predominante na escola brasileira até a década de 40 do século passado.

A ginástica, que é um conhecimento clássico e contemporâneo, entendida como manifestação cultural que agrega elementos técnicos e expressivos na arte de experimentar com o corpo, ao longo da história, tem recebido muitos significados e, em nossos dias, caracteriza-se por diversas manifestações gímnicas - competitivas, de condicionamento físico, fisioterápicas, de conscientização corporal e de demonstração (SOUZA, 1997). Estas se encontram presentes em vários setores sociais e possuem finalidades diferentes de acordo com suas muitas facetas. Assim, o acesso às ginásticas é direito de todo cidadão porque, em conjunto com outras áreas, poderá contribuir para que os alunos participem da construção de uma realidade favorável para si e para todos.

As práticas culturais situadas anteriormente serão discutidas a partir de seu caráter pedagógico na educação física escolar, sendo pensadas em sua articulação teórica por meio do núcleo "o movimento em expressão e ritmo".

Movimento, Porto Alegre, v. 15, n. 04, p. 217-242, outubro/dezembro de 2009. 


\section{MOVIMENTO EM EXPRESSÃo e RITMO NA EdUCAÇÃo FísICA ESCOLAR}

Entendendo as brincadeiras populares, a dança, a expressão corporal e a ginástica como manifestações da produção cultural humana, procuramos caminhos que nos conduzissem ao seu trato, em especial, na educação física escolar. Pelas características de alfabetização corporal, despertar da consciência e sensibilidade, criação, potencial estético-expressivo, diversidade de técnicas corporais, trabalho rítmico, podemos organizá-las em um núcleo, tomando, como exemplo, a classificação proposta por Oliveira (2004). O autor, visando contribuir com a educação física escolar, sugere quatro núcleos de organização do conhecimento: a) o movimento em construção e estruturação; b) o movimento nas manifestações lúdicas e esportivas; c) o movimento e a saúde; d) o movimento em expressão e ritmo. É justamente neste último núcleo que se inserem as brincadeiras populares, a dança, a expressão corporal e a ginástica.

De modo geral, podemos entender o núcleo "o movimento em expressão e ritmo" como aquele que tem por objetivo despertar no educando o acesso ao conhecimento estético-expressivo por meio da consciência do seu corpo, levando-o a experenciar técnicas corporais diversas e próprias de diferentes modalidades, acrescido da dimensão histórico-social que conduz à visualização de como estes saberes fazem parte da produção cultural humana. Numa sociedade marcada pela exacerbação da racionalidade cognitiva e técnico-instrumental, pela mecanização da vida, este núcleo tem um papel fundamental no contexto da educação física, sobretudo porque se coloca como forma de ruptura de padrões sociais vigentes, levando o indivíduo a se perceber como um todo integrado.

Visando identificar formas de abordar o conhecimento neste núcleo, faremos algumas sugestões acerca de como ele pode ser pensado e sistematizado na escola. São orientações na tentativa de auxiliar o docente em seu planejamento, lembrando que estas se pautam em caminhos possíveis, não únicos, de pensar a educação física escolar. Ao professor cabe perceber as formas possíveis de lidar com os saberes, ampliando sua base teórica e fundamentando sua prática peda-

Movimento, Porto Alegre, v. 15, n. 04, p. 217-242, outubro/dezembro de 2009. 
gógica na tentativa de gerir, o melhor possível, o seu trabalho com a educação física mediante a realidade que o cerca.

Tomando como referência o estudo realizado por BarbosaRinaldi (2004) a partir dos conhecimentos que elege para a ginástica, concretizado via pesquisa com docentes que trabalham com saberes gímnicos no ensino superior, faremos apontamentos sobre o trato com estes saberes nas diversas manifestações culturais. Pelo fato da pesquisa voltar-se para uma prática rítmica e expressiva, tal abordagem pode ser transposta para outras manifestações da cultura, como as brincadeiras populares, a dança e a expressão corporal. Algumas orientações explicitadas no quadro 1 advém, ainda, das sugestões de Lara (2003) para o núcleo "o movimento em expressão e ritmo".

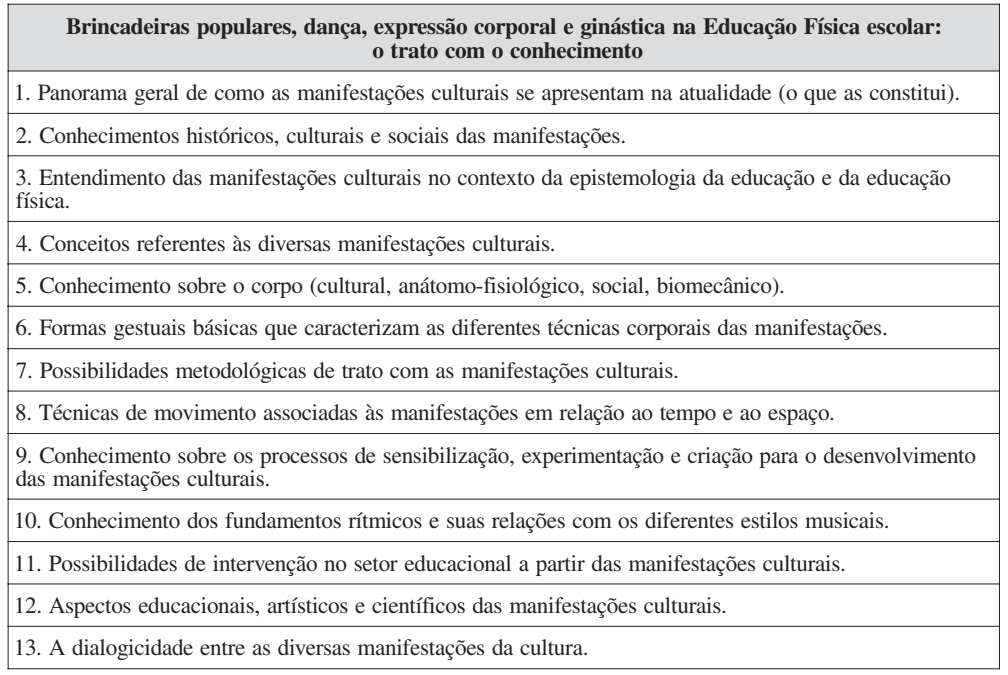

Quadro 1. Conhecimentos rítmico-expressivos para a Educação Física escolar.

Brincadeiras populares, dança, expressão corporal e ginástica podem ser pensadas de forma articulada durante as aulas, ou tratadas de forma individualizada. No que diz respeito às brincadeiras populares, torna-se relevante a construção coletiva (em conjunto com os alunos) do que sejam estas brincadeiras, do porquê da denominação "popular", procurando mapear aquelas que fazem parte, mais diretamente, do núcleo "o movimento em expressão e ritmo".

Movimento, Porto Alegre, v. 15, n. 04, p. 217-242, outubro/dezembro de 2009. 
Num rol de brincadeiras como lenço atrás, gato e rato, cirandacirandinha e caranguejo, é possível identificar aquelas que respondem mais diretamente a um trabalho rítmico e expressivo, e aquelas que objetivam outros aspectos, como o competitivo, o de vertigem ou de sorte, dentro da classificação proposta por Caillois (1986). Lenço atrás e gato e rato, por exemplo, são brincadeiras populares que priorizam o caráter de competição, embora, também, trabalhem o ritmo e conduzam à fantasia. Contudo, nas brincadeiras ciranda-cirandinha e caranguejo, o simulacro é o elemento mais evidente e não o aspecto competição. Elas têm na mimicry (mímica, simulacro, fantasia) seu ponto central. Brincadeiras como pirulito que bate-bate, ponte da vinhaça, Terezinha de Jesus, a linda rosa juvenil, pombinha branca, mocinhas da Europa, seguem a mesma lógica.

No trabalho com as brincadeiras populares é interessante o desenvolvimento de pesquisa com os alunos a partir do que eles conhecem e do que podem conhecer por meio de consulta a livros, revistas, internet, amigos, familiares e outros. Para o núcleo "o movimento em expressão e ritmo" é mister que as brincadeiras priorizadas sejam aquelas que foquem o simulacro, o ritmo e a expressividade, fazendo com que os próprios alunos possam diferenciar os objetivos de uma brincadeira da outra. Além do mais, reinventar uma brincadeira, executando-a de diferentes formas a partir da capacidade criativa do aluno, torna-se crucial na ação educativa, independente dessa modificação dar-se na organização, na melodia, no ritmo, na história, ou em outro aspecto.

Em se tratando do conhecimento de dança é necessário discutir com os alunos o que o termo agrega: o que é dança, quais os tipos existentes, como elas surgem historicamente, por que as pessoas dançam, quais as suas finalidades e características, qual o sentido/significado destas manifestações para as diferentes civilizações, dentre outros questionamentos. Tais reflexões se dão no sentido de organizar um panorama geral de como a dança encontra-se organizada, facilitando a análise crítica dessa manifestação cultural em suas várias nuanças, e de como ela se torna campo de atuação possível ao profissional de educação física.

Movimento, Porto Alegre, v. 15, n. 04, p. 217-242, outubro/dezembro de 2009. 
Ao se pensar em dança, não há como ignorar os processos de sensibilização, experimentação e criação relacionados à preparação do corpo para a pluralidade das manifestações existentes. Trata-se de trabalhar a conscientização do corpo em termos de ritmo próprio e externo, identificando o ritmo das coisas, da natureza, da sociedade (automóveis, eletrodomésticos, sons naturais e culturalmente produzidos, instrumentos de percussão, entre outros). É necessário sensibilizar para a respiração, para os sentidos do corpo (visão, olfato, audição, tato, paladar) e para os vários ritmos existentes (tempos fortes, fracos, músicas de andamento rápido, lento, compassos). Assim, ao mesmo tempo em que se sensibiliza, conquista-se a conscientização das possibilidades corporais por meio da experimentação de diferentes sensações e gestualidades, com o próprio corpo, com o corpo do outro, com ou sem o uso de objetos (latas, pratos, garrafas, pandeiros). Os estudos de Zotovici (1999) contribuem com o entendimento destes processos em dança.

A exploração de movimentos a partir de dinâmicas como tempo, espaço, peso e fluência, conforme os estudos de Laban (1990), assim como ações de pressionar, flutuar, retorcer-se, golpear, deslizar, cortar o ar, dentre outras, é uma forma de preparar o corpo para o seu potencial criativo e não reprodutivo. A partir de então, a capacidade de elaboração e construção coreográfica do aluno é despertada pelas várias combinações possíveis, com a escolha de uma sonoridade diversa que fuja aos padrões estipulados pela mídia e que apenas acentuam o empobrecimento musical.

O uso indiscriminado da dança na educação física escolar é discutido por Sborquia e Gallardo (2002) ao atentarem para o fato de que nem todas manifestações deveriam ser trabalhadas. Estabelecem critérios de cunho ético moral que podem orientar esta seleção, trazendo a seguinte classificação: danças representativas (retratam a relação mítico-religiosa e os costumes de um grupo social), danças sensoriais (ligadas à interpretação musical, de transmissão de sensações e sentimentos por meio do gesto), danças sensuais (representam, sutilmente, pelo olhar e postura corporal a busca de parceiros), danças sexuais (voltadas à procura do parceiro sexual de forma direta, embora disfarçando a gestualidade correspondente ao ato), danças eróticas

Movimento, Porto Alegre, v. 15, n. 04, p. 217-242, outubro/dezembro de 2009. 
(representam a vontade explícita da cópula, revestidas de sentimentos de amor ou paixão) e danças pornográficas (que imitam o ato sexual, seja com parceiro fictício ou objeto, com fins comerciais, provocando a excitação e acentuando o desejo sexual). Entendem que as danças eróticas e as pornográficas são incoerentes ao meio educacional, mas que ao professor cabe o esclarecimento, no contexto escolar, do que sejam estas danças.

Embora a classificação trazida pelos autores não dê conta de agrupar adequadamente todas as danças nas categorias que estabelecem, sobretudo porque a classificação depende mais de como se dança e não da dança em si, ela representa um elemento a mais que pode ser considerado para pensar o processo de formação. Assim, é tarefa do professor elucidar essa seleção, fazendo com que o aluno reconheça o porquê de se priorizar certas manifestações culturais dançantes. Danças veiculadas pela mídia, cujo caráter educacional seja empobrecedor, devem ser debatidas, aguçando a percepção dos alunos e a capacidade crítica para analisá-las.

Mesmo sendo complexa a seleção das danças para o setor escolar, haja vista que mais importante do que a seleção propriamente dita é a forma como cada manifestação vai ser tratada pedagogicamente, entendemos que as danças populares/folclóricas, as danças de salão, a dança moderna/contemporânea, a dança de rua, dentre outras, representam meios interessantes de trabalho a partir da dimensão estético-expressiva. Isso porque, dependendo da maneira como forem desenvolvidas, estas danças favorecem a ampliação das possibilidades gestuais e culturais dos alunos, fomentando reflexões e críticas acerca destas manifestações na sociedade contemporânea.

As danças populares/folclóricas, entendidas como aquelas pautadas na aceitação coletiva e que não se encontram diretamente ligadas à indústria cultural, podem ser desenvolvidas a partir de culturas locais, focando-se as particularidades de cada comunidade nas diferentes regiões brasileiras, bem como mediante o trâmite pela cultura mundial. Representa a compreensão das diferenças culturais de um local para outro, em suas festas, comidas, lendas, músicas, vestimentas, viabilizando outro modo de alfabetizar. Assim, vivenciar os aspectos coreográficos ou a gestualidade típica de determinada manifestação

Movimento, Porto Alegre, v. 15, n. 04, p. 217-242, outubro/dezembro de 2009. 
e seu sentido/significado à comunidade constitui-se numa das necessidades do ato educativo.

Ao contrário da coletividade própria das danças populares/folclóricas, a dança de salão caracteriza-se por uma técnica corporal apurada (no sentido de maior exigência em termos de gestualidade), sendo realizada, geralmente, aos pares. Sua constituição, decorrente do momento de transformação das danças de corte, vai se dando, gradativamente, até chegarmos aos ritmos conhecidos hoje - valsa, bolero, tango, merengue, forró, e outros. Os aspectos históricos advindos de investigações realizadas por Lessa, Cortes (1975) representam aportes para a percepção desta trajetória histórica. Essa indicação dáse pelo entendimento de que tais danças não devem ser trabalhadas desprovidas da historicidade que as permeia e da cultura representativa de cada país. Ou seja, como abordar o tango sem mencionar a cultura argentina? Como falar de samba e forró e não falar de Brasil? Como discutir salsa e não abordar a cultura cubana?

Embora os ritmos (música e dança) surjam em determinado país, passam a ser mundializados quando levados e difundidos para outras culturas. No ensino desta modalidade no setor escolar, o mais importante não é a técnica em si (embora ela seja considerada), mas situar estas manifestações em sua pluralidade cultural. Os ritmos a serem trabalhados dependerão dos objetivos educacionais, das séries escolares, da realidade local e da responsabilidade do professor e do aluno nesta seleção. Tais cuidados são necessários como forma de se evitar a abordagem única de ritmos massivos e da técnica pela técnica, comprometendo o ato educativo.

Um exemplo de manifestação dançante que se ramificou para outros países é a dança de rua. Surgida nos guetos norte-americanos, na década de 60 do século XX, esta dança foi, aos poucos, ancorando em solo brasileiro. A gestualidade forte, de ritmo intenso, de letra contestadora, de luta e protesto, ganha força a partir de ações conjuntas por meio de um movimento cultural conhecido como Hip-Hop. Por sua característica despojada, acrobática, criativa e altamente rítmica, a dança de rua representa uma manifestação a ser desenvolvida na educação física escolar. Músicas cujas narrativas foquem injustiças, 
medos, preconceitos, marginalidade, sonhos, podem ser temáticas geradas da realidade dos alunos e, também, de suas necessidades de vivência gestual.

Intimamente ligada a uma necessidade gestual que fuja a padrões estereotipados de movimento está a dança contemporânea, tratada por alguns estudiosos no contexto escolar como dança-educação, dança educativa, dança criativa, dentre outras denominações. Além dessas possibilidades de definição, o próprio entendimento de dança contemporânea não é consensual, podendo, hoje, ser percebida como sinônimo de dança moderna ou tratada diferentemente a partir de sua conjuntura histórica. Independente dos termos utilizados, o mais importante é priorizar o trabalho com uma manifestação corporal rica em diversidade de movimentos e temáticas, de potencial críticoreflexivo, de fuga à banalização do gesto na contemporaneidade. Tem como características a apropriação de temas do cotidiano, a preocupação em não se negar absolutamente nada, a ausência de fronteiras culturais e estilísticas, a heterogeneidade do corpo dançante, bem como a simultaneidade de focos (cenas múltiplas). Tais características fazem desta forma de expressão uma das mais ricas a ser desenvolvida no contexto educacional na medida em que não discrimina o menos habilidoso, mas prioriza as diferenças. As músicas fogem a qualquer caráter massivo, sendo retratada pelo próprio silêncio, pelos ritmos corporais, pelas diversas percussões e pelo não banalizado.

É certo que outras manifestações dançantes podem ser, ainda, desenvolvidas nas escolas, como o balé clássico, o jazz, a dança do ventre, a dança afro-brasileira, dentre outras. Contudo, é importante esclarecer os objetivos educacionais resultantes desse trabalho na tentativa de assegurar não apenas a diversidade das manifestações, mas, notadamente, a qualidade das abordagens. Não cabe ao professor o domínio de todas as manifestações dançantes, mesmo porque essa seria uma tarefa homérica. Seu papel é atuar como mediador de modo que o aluno possa ter acesso ao conhecimento, modificando, transformando e intervindo, bem como apreendendo os saberes relevantes à sua formação. É necessário que oportunize ao aluno o conhecimento sobre as diferenças de uma manifestação dançante em 
relação à outra, de sua constituição histórica, de suas técnicas corporais. Isso pode ser feito mediante um conjunto de ações, como valorizar as próprias experiências dançantes dos alunos, convidar profissionais que atuam com distintas modalidades para ir à escola, levar os alunos a espaços em que as manifestações dançantes sejam realizadas (academias, teatros, espaços públicos, entre outros), incentivar pesquisas a livros, revistas, jornais e fontes online, conduzi-los para o acesso a filmes e documentários que tratem da temática.

No tocante à expressão corporal, é preciso assegurar que os alunos compreendam seu sentido/significado, identificando como a expressão cotidiana pode ser trabalhada e transformada em expressão artística e extracotidiana. Sugerimos experiências que potencializem a representação de sensações e sentimentos (alegria/tristeza, dor, nervosismo, calmaria, agitação e outros); a imitação de coisas, animais e pessoas; a realização de mímica (expressão de ideias por meio de gestos); a representação de personagens cotidianos, históricos, reais ou fictícios; a estimulação dos sentidos do corpo (auditivo, visual, tátil, olfativo e gustativo); a criação a partir de temas-geradores (poemas, filmes, músicas, notícias), bem como outras representações.

Cabe ressaltar que o trabalho de expressão corporal deve conduzir o aluno a externar seus sentimentos, a superar suas limitações gestuais e a timidez que dificulta qualquer forma de comunicação. Para isso, jogos de expressão corporal podem ser utilizados no sentido de facilitar o envolvimento do aluno de forma lúdica, como desenvolver um tema em específico (piquenique, filme, presente de grego, noite no circo), comunicar palavras a ser descobertas por um grupo, expressar diferentes efeitos sonoros e outros. A discussão de determinado tema, a criação de um personagem, a realização de laboratórios que ajudem a construir e a consolidar dado personagem, são algumas das possibilidades educativas, acrescidas de pesquisa sobre o assunto. Podem ser utilizados o silêncio, músicas, sons diversos (instrumentos, objetos, papéis, percussão no corpo e outros). Algumas das sugestões a esse respeito são encontradas em Stokoe e Harf (1987), bem como em Fassina, Pereyra e Cena (2002). A expressão corporal, nesta sociedade racional, deve ser amplamente debatida como tema fundamental do processo educativo.

Movimento, Porto Alegre, v. 15, n. 04, p. 217-242, outubro/dezembro de 2009 
Pensando no trato com a ginástica, as questões históricas (como surge, a que fins visa atender, qual seu papel junto à história da educação física, quais os modismos que permeiam esta manifestação, bem como seu potencial crítico) são alguns dos saberes a ser desenvolvidos. Podem ser exploradas, ainda, formas básicas de movimento (andar, correr, saltar, rolar, trepar, e outras) a partir de variações rítmicas e sonoras, ou por meio da diversidade de situações criadas pelos alunos. Objetos construídos por eles próprios (balanços, pernas-de-pau, túneis de tecido) ou existentes na escola (escada, pneus, bolas, cordas) representam meios de abordar as diversas formas gímnicas presentes na contemporaneidade, como a ginástica rítmica, a ginástica artística, a ginástica acrobática e a ginástica geral.

A ginástica rítmica (GR) é uma modalidade competitiva que trabalha com a manipulação de aparelhos. Está associada à música e a uma gestualidade própria, de movimentos totais e fluentes. Historicamente, nasce do campo dos divertimentos, do uso do corpo como entretenimento/espetáculo em ruas, praças públicas, feiras, circos, em especial, no que diz respeito aos movimentos de manipulação (malabarismo). Seu papel na educação física escolar não deve ser o de focalizar apenas os gestos da técnica nos padrões do esporte de rendimento, mas sim de levar o aluno a compreender esta manifestação da cultura por meio da exploração gestual e de seus significados. Para isto, podem ser utilizados aparelhos oficiais/tradicionais e, também, materiais confeccionados pelos alunos, como cordas de papel jornal encapadas com fita adesiva, arcos de PVC, bolas de papel jornal ou meia, maças de garrafa plástica com pedaço de madeira, faixas e fitas de tecido ou crepom.

Temas que provoquem reflexão, análise e crítica podem subsidiar o trato com a ginástica rítmica na escola. Dentre eles podemos citar: a padronização e estética dos movimentos da GR (postura corporal, entre outros aspectos); as características desta manifestação como esporte feminino e masculino; os padrões de corpo dessa modalidade como esporte de rendimento; a (não) política de desenvolvimento esportivo no país; a busca de um conceito próprio de GR que possibilite a participação de todos.

Movimento, Porto Alegre, v. 15, n. 04, p. 217-242, outubro/dezembro de 2009. 
Outra manifestação gímnica que pode ser trabalhada na escola é a ginástica acrobática, apresentada pela FIG (2005) como sendo uma modalidade esportiva que trabalha com elementos acrobáticos coletivos e individuais de extrema dificuldade, em perfeita harmonia e sincronismo. Outro dado importante é que esta ginástica se difere dos demais desportos gímnicos pela ausência de aparelhos. Os praticantes dessa modalidade têm o espaço para desenvolver coragem, força, flexibilidade, assim como cooperação e ajuda mútua. Isto porque o ginasta é o alicerce que assegura e promove as figuras acrobáticas.

Vale ressaltar que a experimentação dessa ginástica na escola pode acontecer em espaços diferenciados e, por não requerer a utilização de materiais, contribui significativamente para o enriquecimento das relações sociais. O trabalho com a ginástica acrobática pode e deve dar ênfase à formação humana, haja vista que não requer alto nível de execução dos educandos. A dependência uns dos outros nos exercícios em equipe gera responsabilidade na relação da coletividade.

A discussão acerca da ginástica artística como conhecimento da educação física escolar refere-se, em essência, à importância desse conhecimento, bem como à criação de possibilidades de trabalho em meio escolar. Talvez um caminho que possa facilitar esse entendimento seja o de compreendê-la a partir de sua construção histórica, já que também esta ginástica nasce do campo dos divertimentos, do uso do corpo como entretenimento/espetáculo em ruas, praças públicas, feiras, circos essencialmente, a partir das acrobacias livres e em aparelhos. Desse modo, percebemos que seu núcleo primordial de movimentos parte da necessidade da movimentação cotidiana do homem (andar, correr, saltar, dentre outros), assim como dos gestos que rompem com os padrões de movimentos comuns (inversões de eixo longitudinal, trabalhos de excessiva força, elasticidade e agilidade).

Embora sejam muitas as manifestações gímnicas possíveis de ser desenvolvidas na escola, vemos na ginástica geral uma forma especial de educar. Isso porque a ginástica geral precede as ginásticas de competição e, ainda, representa, com base em Soares (1999), uma bem sucedida (re)significação das primeiras manifestações ginásticas, 
presente nos gestos ousados dos acrobatas, na alegria dos funâmbulos e das brincadeiras infantis. Mescla as diferentes ginásticas, a dança, o teatro, a capoeira, os elementos circenses, entre outras, sendo explorada por experiências coletivas com ou sem utilização de materiais. Além do mais, poder ser construída a partir dos saberes inscritos na cultura popular, nos saberes filosóficos, nos saberes artísticos e, também, nos saberes científicos. $O$ trato com a ginástica geral deve ser orientado para que todos os alunos possam dela participar, promovendo o respeito aos limites de cada um, privilegiando as diferentes potencialidades e respeitando a subjetividade do gesto. Voltamos nosso olhar para o desenvolvimento de uma ginástica geral inclusiva, democrática, permitindo o conhecimento e a produção dos saberes gímnicos em todas as suas dimensões, o que poderá conduzir o aluno a uma formação humana diferenciada.

As manifestações gímnicas apresentadas, além do aspecto técnico, apresentam um potencial educativo e cultural de valorização do campo gestual. Nesse sentido, a sensibilização, a experimentação e a criação sugeridas para a dança também se colocam como necessidade prioritária do trabalho com ginástica. Algumas sugestões de como desenvolver este conhecimento na escola podem ser obtidas em Barbosa-Rinaldi (2004).

O trabalho com as práticas corporais elegidas para este texto demanda uma sensibilização que leve o educando a ter noções de ritmo, de técnicas respiratórias, de expressão corporal, bem como a reconhecer suas limitações gestuais e seu potencial criativo. Implica, ainda, no domínio de seus fundamentos histórico-sociais, estéticos, biológicos, antropológicos, dentre outros. Pelas brincadeiras populares, dança, expressão corporal e ginástica o corpo é levado a experimentar os mais diversos movimentos em suas variações de tempo, espaço, peso e fluência, nas inúmeras combinações possíveis, sendo impulsionado a criar, a analisar, a criticar, a compor, a organizar a gestualidade individual/ coletiva e a expressar-se. É a partir desse reconhecimento corporal que a diversidade de manifestações passa a ser explorada, focando não apenas o que regionalmente é trabalhado, mas valorizando, sobretudo, as expressões que se tornam mundializadas por uma necessidade coletiva de comunicação.

Movimento, Porto Alegre, v. 15, n. 04, p. 217-242, outubro/dezembro de 2009. 


\section{CONSIDERAÇõES FINAIS}

A abordagem de questões relativas ao processo de (re)significação da educação física escolar que ora se intenta por este texto traduz reflexões sobre a produção do conhecimento na área, a possibilidade de acesso aos saberes sistematizados, as práticas culturais estéticoexpressivas e o núcleo "o movimento em expressão e ritmo". Tal intento buscou, entretanto, incursões pelos vários saberes que a área oferece, mas focou os conhecimentos que se inserem na dimensão rítmica e expressiva, haja visto que este campo da racionalidade/ sensibilidade, ainda, é pouco explorado no contexto da escola. Não tivemos a intenção de apresentar propriamente uma sistematização de trabalho com estes conhecimentos, mas sim de atentar para possíveis encaminhamentos em relação ao trato com as manifestações apresentadas, visando contribuir com a ação docente.

A produção do conhecimento em educação física foi discutida como fenômeno complexo que se materializa pela ação social dos homens a partir de necessidades investigativas e existenciais, sendo que o acesso a essa produção representa uma forma de garantir, por vias democráticas, que educadores e educandos venham a conhecer e (re)significar os diversos saberes. As práticas culturais estético-expressivas foram tratadas pelas brincadeiras populares, pela dança, pela expressão corporal e pela ginástica, entendendo que elas oferecem um vasto manancial a ser desenvolvido nas aulas de educação física, embora nem sempre cuidadosamente reconhecidos e abordados na escola. A visualização do núcleo "o movimento em expressão e ritmo" procurou satisfazer o interesse pela percepção das práticas corporais estético-expressivas em suas relações de autonomia e dependência, em sua capacidade de mediação/interação, abrindo possibilidades para que o docente, ao mesmo tempo em que identifique suas peculiaridades, perceba seus limites tênues.

Entendemos ser urgente a (re)significação da Educação Física partindo da compreensão de que a educação, como salienta Hermann (2005, p. 110), apresenta vários caminhos a seguir, cuja estruturação "não deve priorizar o estritamente racional, mas, ao contrário, dar expressão às diferentes formas de atividades criadoras". A constituição 
do ser humano dá-se pela pluralidade de experiências e abertura ao mundo e ao outro, tendo a experiência estética assumido um sentido eminentemente formativo. É pensando na possibilidade de um sujeito em formação que seja potencializado para uma ação ético-estética, autônoma, sensível/racional e emancipatória que vislumbramos o trato com a educação física no setor escolar.

A compreensão do núcleo "o movimento em expressão e ritmo" dá-se no sentido de que o professor de educação física atente para a necessidade de contemplá-lo em sua prática pedagógica, explorando potencialmente conhecimentos que, por vezes, tornam-se meros apêndices do processo educacional. Isto se deve, em grande parte, a inúmeros fatores, dentre os quais o descrédito, na sociedade, pelos conhecimentos que foquem a racionalidade estético-expressiva, a falta de experiências do professor nesta área (o que faz com que se sinta incapaz de trabalhá-los), a visualização de uma educação física meramente esportiva/competitiva e a resistência dos alunos a conhecimentos que, culturalmente, não lhes são postos como essenciais. Sendo assim, iniciativas que visem ampliar a percepção sobre a pluralidade dos saberes e contribuir com sua ação efetiva na educação física escolar tem o seu mérito e sua ação transformadora.

Movimento, Porto Alegre, v. 15, n. 04, p. 217-242, outubro/dezembro de 2009. 
240 Ensaios Iara Rinaldi, Larissa Lara e Amauri de Oliveira

Contributions to process of (re)meaning of the scholar Physical Education: dimensions of popular children's games, dance, corporal expression and gymnastics

Abstract: This text aims to present pedagogical and teaching ideas for scholar physical education from the core "movement in expression and rhythm", proposed by Oliveira (2004). Such considerations involve conceptual aspects, field of knowledge and methodological guidelines to deal with the following skills: popular children's games, dance, gymnastics and corporal expression. The intention of this theoretic approach is to propose routings that can support the work of teacher, instigating him to dialogue with the rhythmicexpressive knowledges and, consequently, with its materialization in scholar daily.

Keywords: Education, primary. Knowledge. Physical Education. Play and playthings.

\begin{abstract}
Contribuciones al processo de (re)significación de la Educación Física escolar: dimensiones de los juegos populares, de la danza, de la expresión corporale y de la gimnasia

Resumen: Este texto presenta reflexiones didácticopedagógicas para la educación física escolar a partir del núcleo "el movimiento en expresión y ritmo", propuesto por Oliveira (2004). Tales reflexiones involucran aspectos conceptuales, campo de conocimiento y orientaciones metodológicas para el tratamiento con los siguientes saberes: juegos populares, danza, expresión corporal y gimnasia. La intención de ese acercamiento teórico es proponer direcciones que subvencionen el trabajo del profesor, de modo que el haga diálogo con los conocimientos rítmico-expresivos y, por consiguiente, con su materialización en el cotidiano escolar.

Palavras clave: Educación primaria. Conocimiento. Educación Física. Juego e implementos de juego.
\end{abstract}

\title{
REFERÊNCIAS
}

AYOUB, Eliana. Ginástica geral e educação física escolar. Campinas, SP: UNICAMP, 2003.

BARBOSA-RINALDI, leda Parra. A ginástica como área de conhecimento na formação profissional em educação física: encaminhamentos para uma

Movimento, Porto Alegre, v. 15, n. 04, p. 217-242, outubro/dezembro de 2009. 
Contribuições ao processo de (re)significação da Educação Física escolar..

estruturação curricular. 2004. Tese (Doutorado em Educação Física) - Faculdade de Educação Física, Universidade Estadual de Campinas, Campinas, 2004.

CAILLOIS, Roger. Los juegos y los hombres: la máscara y el vértigo. México: Fondo de Cultura Económica, 1986.

CORTELLA Mario Sergio. Escola e o conhecimento: fundamentos epistemológicos e políticos. São Paulo: Cortez, 2000.

FASSINA, Mirtha; PEREYRA, Cecília; CENA, Marcela. Experiencia de si y problematizaciones en las prácticas corporales. Córdoba, Argentina: Alción, 2002.

FEDERATION INTERNATIONALE DE GYMNASTIQUE (FIG). Acrobatic Gymnastics. Disponivel em: http://www.sportcentric.com/vsite/vnavsite/page/directory/0,1085 3,5187-188459-205681-nav-list,00.html. Acesso em: 15 dez. 2005.

GARAUDY, Roger. Dançar a vida. Rio de Janeiro: Nova Fronteira, 1980.

HERMANN, Nadja. Ética e estética: a relação quase esquecida. PortoAlegre: EDIPUCRS, 2005

KELLY, Albert Victor. O currículo: teoria e prática. São Paulo: Harper \& Row do Brasil, 1981.

LABAN, Rudolf. Dança educativa moderna. São Paulo: Ícone, 1990.

LARA, Larissa Michelle. O movimento em expressão e ritmo: encaminhamentos estruturais e metodológicos para a educação física escolar. In: CONGRESSO BRASILEIRO DE CIÊNCIAS DO ESPORTE, 13., 2003, Caxambu. Anais... (Publicado em CD-Rom).

LESSA, Barbosa; CORTES, Paixão. Danças e andanças da tradição gaúcha. 2. ed. Porto Alegre: Garatuja, 1975.

MAUSS, Marcel. Sociologia e antropologia. São Paulo: EPU, 1974.

OLIVEIRA, Amauri. Planejando a educação física escolar. In: VIEIRA, José Luiz Lopes. Educação física e esportes: estudos e proposições. Maringá: EDUEM, 2004.

PIMENTA, Selma Garrido. Professor reflexivo: construindo uma crítica. In: PIMENTA, Selma Garrido; GHEDIN, Evandro (Org.). Professor reflexivo no Brasil: gênese e crítica de um conceito. São Paulo: Cortez, 2002. p.17-52.

PUJADE-RENAUD, Claude. Linguagem do silêncio: expressão corporal. São Paulo: Summus, 1990.

SBORQUIA, Silvia Pavesi; GALLARDO, Jorge Sérgio Pérez. As danças na mídia e as danças na escola. Revista Brasileira de Ciências do Esporte, Campinas, v. 23, n. 2, p.105-118, jan., 2002.

SOARES, Carmem Lucia. et al. Metodologia do ensino da educação física. São Paulo: Cortez, 1992.

Movimento, Porto Alegre, v. 15, n. 04, p. 217-242, outubro/dezembro de 2009. 
242 Ensaios Iara Rinaldi, Larissa Lara e Amauri de Oliveira

SOARES, Carmem Lúcia. O corpo, o espetáculo, a ginástica. In: FÓRUM BRASILEIRO DE GINÁSTICA GERAL; 1999, Campinas. Anais... v. 1, p.19-21.

SOUZA, Elizabeth Paoliello Machado de. Ginástica Geral: uma área do conhecimento da Educação Física. 1997. Tese (Doutorado em Educação Física) - Faculdade de Educação Física, Universidade Estadual de Campinas, Campinas, 1997.

STOKOE, Patrícia; HARF, Ruth. Expressão corporal na pré-escola. São Paulo: Summus, 1987.

ZOTOVICI, Sandra Aparecida. Dança-educação: uma experiência vivida. Conexões: Educação, Esporte, Lazer, Campinas, n. 3, p.119-128, dez., 1999.

ZUIN, Antônio Álvaro Soares. Indústria cultural e educação: o novo canto da sereia. Campinas, SP: Autores Associados, 1999.

Recebido em: 31.12.2008

Aprovado em: 06.07.2009

Movimento, Porto Alegre, v. 15, n. 04, p. 217-242, outubro/dezembro de 2009. 